DOE/RL-93-24-5

UC-510, 702, 705, 721

\title{
Hanford Environmental Information System (HEIS) Volume 5 Surface-based Subject Areas
}

Date Published

January 1994

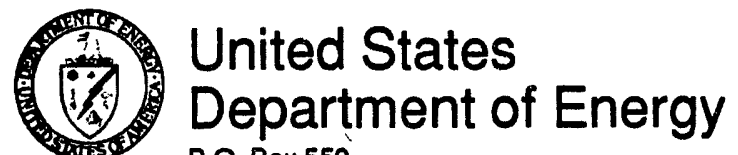

P. Box 550

Richland, Washington 99352

Selentific and Technical Computer Sottware This computer soltware has been devoloped undor sponsorship of the S. Departmont the Director, Energy Sciences and Tectnology Soltware Center, P.O. Bcx 1020, Oak Ridgo, Tonnesseo 37831. 
LEGAL DISCLAIMER

This report was prepared as an account of work sponsored by an agency of the United States Government. Neither the United States Government nor any agency thereof, nor any of their employees, nor any of their contractors, subcontractors or their emplo; 9es, makes any warranty, express or implied, or assumes any legal liability or responsibility for the accuracy, completeness, or any third party's use or the results of such use of any information, apparatus, product, or process disclosed, or represents that its use would not infringe privately owned rights. Reference herein to any specific commercial product, process, or service by trade name, trademark, manufacturer, or otherwise, does not necessarily constitute or imply its endorsement, recommendation, or favoring by the United States Government or any agency thereof or its contractors or subcontractors. The views and opinions of authors expressed herein do not necessarily state or reflect those of the United States Government or any agency thereof.

This report has been reproduced from the best available copy. Available in paper copy and microfiche.

Available to the U.S. Department of Energy and its contractors from

Office of Scientific and Technical Information P.0. Box 62

Oak Ridge, TN 37831

(615) 576-8401

Available to the public from the U.S. Department of Commerce National Technical Information Service

5285 Port Royal Road

Springfield, VA 22161

(703) $487-4650$

Printed in the Unitod States of America

DISCLM-1.CHP (1-91) 


\section{CONTENTS}

1.0 THE ATMOSPHERIC SUBJECT AREA

2.0 THE BIOTA SUBJECT AREA

2.1 OVERVIEW

2.2 ACCESSING BIOTA DATA

2.3 THE BIOTA TABLES

2.3.1 BIOTA SAMPLE TABLE

2.3.2 BIOTA RESULT TABLES

2.3.2.1 Biota Result Table

2.3.2.2 Biota Result Change Table

2.3.3 BIOTA POPULATION TABLE

2.3.4 BIOTA DISTRIBUTION TABLE

2.3.5 BIOTA SPECIES TABLE

2.3.6 BIOTA REPORTING GROUP TABLE

3.0 THE SURFACE WATER SUBJECT AREA

3.1 OVERVIEW

3.2 ACCESSING SURFACE WATER DATA

3.3 THE SURFACE WATER TABLES

3.3.1 SW SAMPLE TABLE

3.3.2 SW RESULT TABLES

3.3.2.1 SW Result Table

3.3.2.2 SW Result Change Tables

4.0 THE RIVER CHARACTERISTICS SUBJECT AREA

\section{FIGURES}

2.1-1 Data Model Showing Relationships Among the Tables in the Biota Subject Area and Their Relationships with Tables Located in Other HEIS Subject Areas

2.2-1 Biota Menu

2.2-2 Map of Biota Entry Points

2.3.1-1 Biota Sample Form

2.3.2.1-1 Biota Result Form

2.3.2.1-2 Biota Result Multiple View Form

2.3.2.2-1 Biota Result Change View Form

2.3.3-1 Biota Population Form 
Section

Page

Date

2.3.4-1 Biota Distribution Form

2.3.5-1 Biota Species Form

$3.1-1$

Data Model Showing Relationships Among the Tables in the Surface Water Subject Area and Their Relationships with Tables Located in Other HEIS Subject Areas

$3.2-1$

Surface Water Menu

$3.2-2$

Map of Surface Water Entry Points

$3 \cdot 3 \cdot 1-1$

SW Sample Form

$3 \cdot 3 \cdot 2 \cdot 1-1$

$3.3 \cdot 2.1-2$

$3 \cdot 3 \cdot 2 \cdot 2-1$ 
DOE/RL-93-24-5

Section

Page

Date

1 of 2

$01 / 14 / 94$

\subsection{THE ATMOSPHERIC SUBJECT AREA}

To be issued. 
Section

Page

Date

This page intentionally left blank. 


\subsection{THE BIOTA SUBJECT AREA}

\subsection{OVERVIEW}

PURPOSE

SCOPE
The purpose of the Biota subject area of the Hanford Environmental Information System (HEIS) is to manage the data collected from samples of plants and animals. This includes both samples taken from the plant or animal or samples related to the plant or animal. Related samples include animal feces and animal habitat (e.g., litter found in the animal's burrow).

Data stored in the Biota subject area include data about the biota samples taken, analysis results, counts from population studies, and species distribution maps.

There are four major types of data that make up the Biota subject area:

- Samples--Samples include specimens sent to a labcratory for analysis. Characteristics about the sample itself are stored in the Biota Sample table.

- Laboratory analysis of biota samples--Specimens can be analyzed using a variety of protocols. The results of all types of analyses are stored in the Biota Result table.

- Population studies--Populations of a plant or animal are counted. The Biota Population table contains the actual count per unit area. The Biota Sample table describes the organism counted, the date(s) of counting, the location where the sample was collected, and other descriptive information.

- Biota distribution studies--Geographic areas are mapped for the density of a plant or animal. The Biota Distribution table contains information about the map generated to depict this distribution. Currently, only the map identifier (ID) and a description of the map are stored in the HEIS database. In the future, the distribution map, known as an overlay, will be stored within the HEIS Geographical Information System (GIS). The Biota Sample table describes the organism mapped, the date(s) of mapping, the 
Section

Page

Date

DATA MODEL

TERMINOLOGY

station where the sample was collected, and other descriptive information.

Figure 2.1-1 is a data model showing relationships among the tables in the Biota subject area tables and their relationships with other HEIS tables. The associations are described below. Capitalized items refer to both the actual item and the Biota table in which data about that item are stored.

Each Biota Sample record may have several records in the Biota Result table, or it may be associated with a Biota Population record or a Biota Distribution record.

Each Biota Sample record may have an associated location, which can be specified in one of two ways. If the same location will be resampled, then a Sampling Site is used. If this is a "grab" sample and no resampling at this point is expected, an Entity Point Location is used. By using either the Sampling Site or Entity Point Location, Lambert coordinates can be provided for the location.

Each Biota Sample record may have one or more Biota Result Change records. These records will exist if the Biota Result record was changed.

The organism associated with a biota sample is identified using the following three fields in the Biota Sample record:

- Biota Media identifies what class of organism was sampled. Choices are vegetation, wildlife, and commercial foodstuff. Commercial foods are identified separately because the same organism may be sampled both as a food and as a naturally occurring plant. Asparagus is an example.

- Common Name identifies the exact organism that was sampled. For many organisms, the Common Name can be associated with the equivalent Species, the latin binomial. Some common names, such as algae, represent more than one species; thus, no Species is provided. Table 2.1-1 lists some of the more frequently used Common Name(s) and Species currently in HEIS. 
Figure 2.1-1. Data Model Showing Relationships Among the Tables in the Biota Subject Area and Their Relationships with Tables Located in Other HEIS Subject Areas.

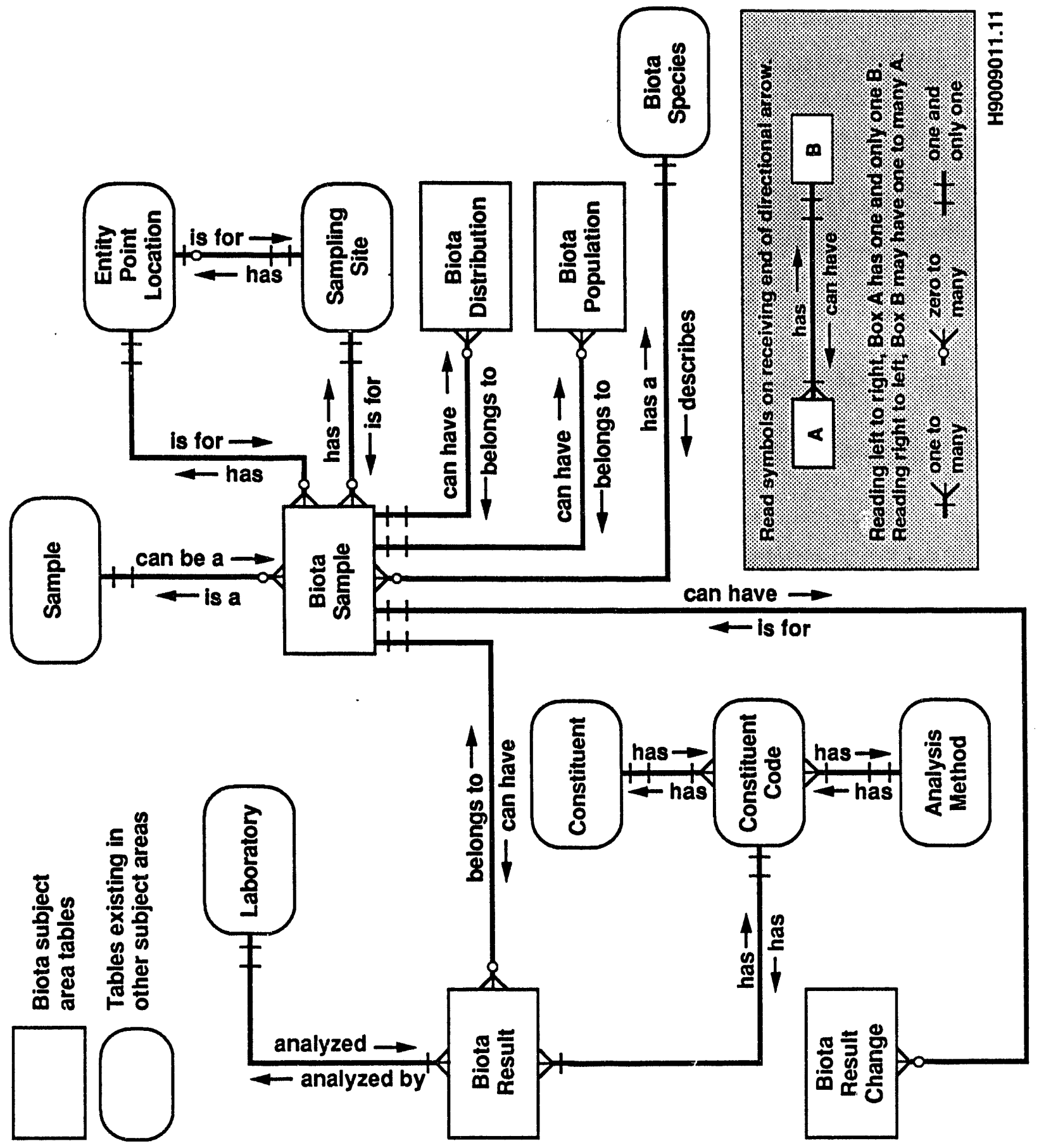


Table 2.1-1. Common Names and Species for HEIS Biota Data.

\begin{tabular}{ll}
\hline \multicolumn{1}{c}{ Cormon Name } & \multicolumn{1}{c}{ Species } \\
\hline gray rabbitbrush & Chrysothamus nauseous \\
green rabbitbrush & Chrysothamus viscidiflorus \\
Sandberg's bluegrass & Poa sandbergi i \\
reed canary grass & Phalaris arundinacea \\
white mulberry & Morus alba \\
black cottonwood & Populus trichocarpa \\
black locust & Robinia pseudo-acacia \\
asparagus & Asparagus officinalis \\
elm & Ulmus sp \\
willow & Salix sp \\
common cattail & Typho latifolia \\
Russian thistle & Salsola kali \\
big sagebrush & Artemisia tridentata \\
cheatgrass & Bromus tectorum \\
harvester ant & Pogonomyrmex owyeei \\
house mouse & Mus musculus \\
Great Basin pocket mouse & Perognathus parvus \\
caddisfly & Trichoptera \\
coyote & Canis latrans \\
red-tailed hawk & Buteo jamaicensis \\
milfoil & Myriophyllum spicatum \\
algae & \\
mice & \\
clams & \\
insects & \\
ants & \\
\hline
\end{tabular}


- Sampled Portion identifies the portion of the organism that was included in the sample. Choices include whole organism, stems and leaves, bone, liver, muscle, and anima? habitat. The portion of the organism that was analyzed may be important in correctly interpreting the levels of various constituents reported by the analysis laboratory.

MENU SYSTEM

USERS

REPORTS
The Biota subject area allows you to navigate among the Biota forms using the HEIS query-by-form interface. Section 2.2 describes how to access the various Biota forms using this interface. The Biota tables are described in Section 2.3.

The users of the Biota subject area are (1) technical staff interested in data related to biologic samples, (2) technical staff interested in the contamination found when the samples are analyzed for the presence of various constituents in the laboratory, (3) data processing staff responsible for inserting and maintaining the biota data, and (4) technical staff at regulatory agencies interested in monitoring the levels of various contaminants found in the samples.

Reporting information is provided in Section 2.4 (to be issued). 
Section

Page

Date
2.1

6 of 6

$01 / 14 / 94$
DOE/RL-93-24-5

This page intentionally left blank. 


\subsection{ACCESSING BIOTA DATA}

INTRODUCTION

The Biota menu, presented in Figure 2.2-1, shows the entry points into the Biota forms. Figure 2.2-2 is a diagram of how these forms and other forms are connected. See Section 5.3 of the HEIS User's Guide (DOE-RL 1994a) for a detailed description of entry point maps. Section 2.3 describes each of the tables and forms associated with individual entry points.

Figure 2.2-1. Biota Menu. HANFORD ENVIRONMENTAL INFORMATION SYSTEM Biote Subject Area

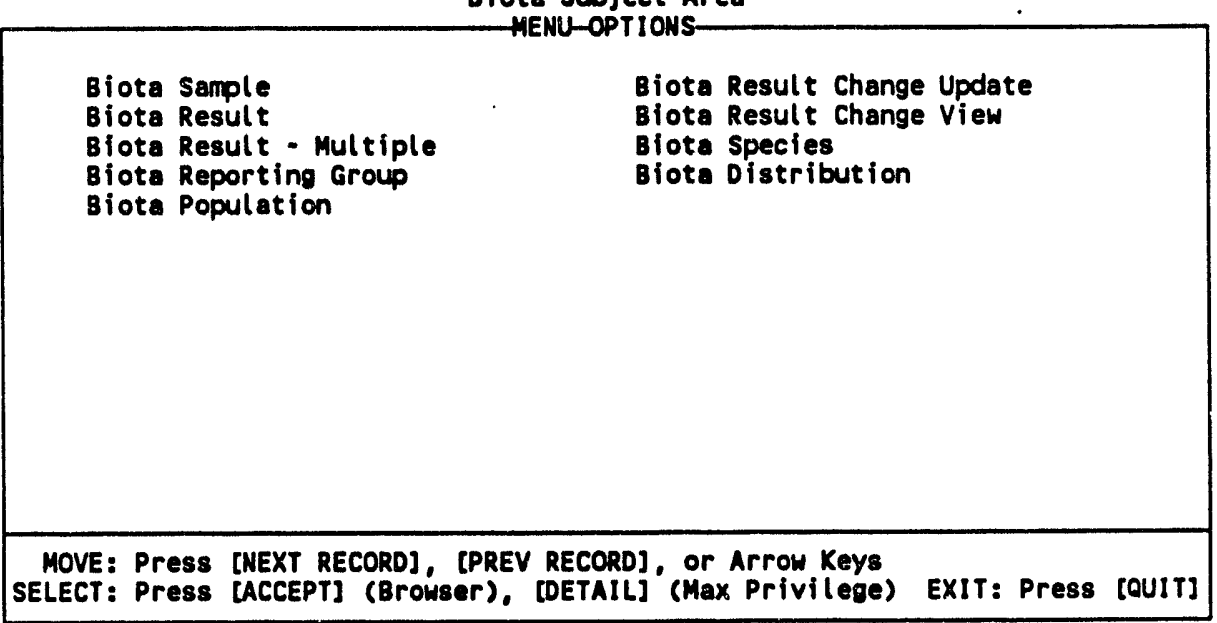


Section

Page

Date

Figure 2.2-2. Map of Biota Entry Points.

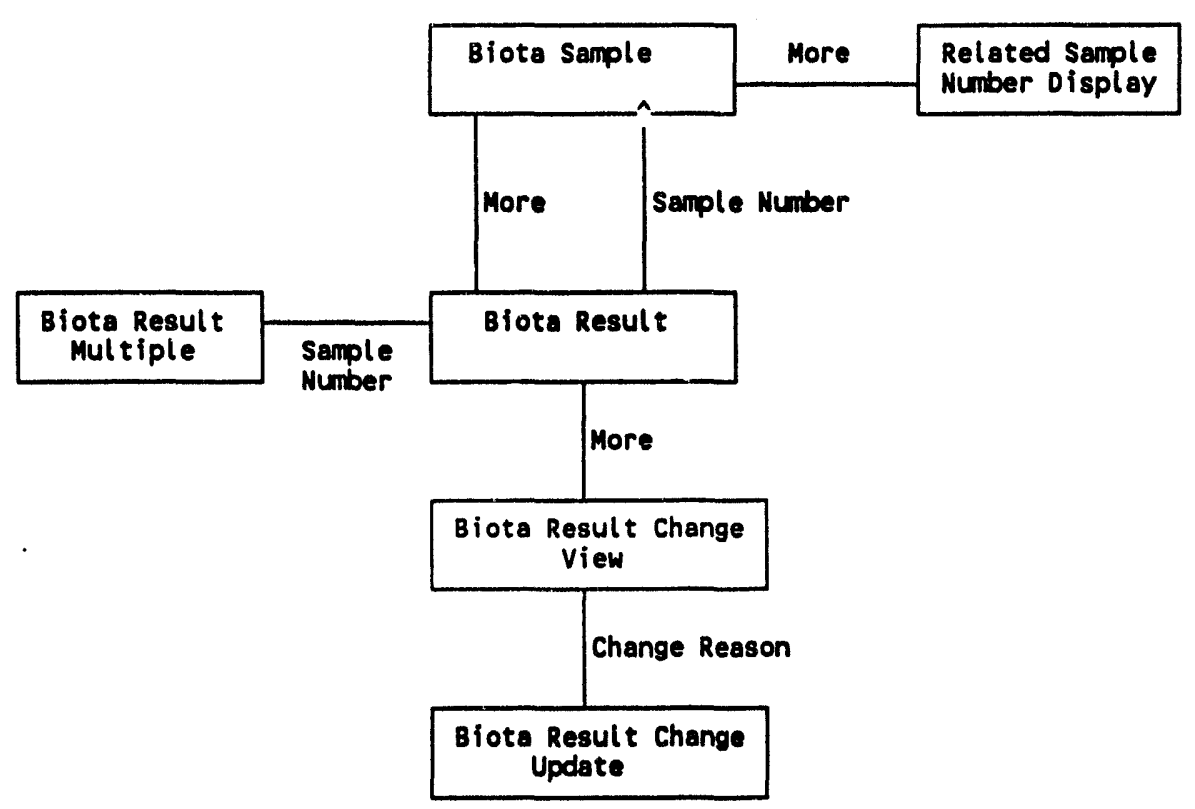

Biota Population

Biota Reporting Group 


\subsection{THE BIOTA TABLES}

\subsubsection{BIOTA SAMPLE TABLE \\ (HEIS Database Table Name: biota_sample)}

\section{INTRODUCTION}

SOURCE

\section{REQUIREMENTS}

Dependencies
The Biota Sample table contains data about the following:

- Plant or animal samples taken for laboratory analysis, including both samples taken from the plant or animal or samples related to the plant or animal. Related samples include animal feces and animal habitat (e.g., litter found in the animal's burrow).

- Population counts performed

- Distributional mapping.

Each Biota sample is uniquely identified by a sample number. Other important data are the identification of the biologic organism sampled, the sampled portion, media, common name, location at which the sample was collected, and the date of sampling. The Biota Sample form is shown in Figure 2.3.1-1.

Data for this table come from field log books, which are filled out during sampling.

Data for this table are also generated automatically by the Pacific Northwest Laboratory (PNL) to support routine biota monitoring activities.

Composite Sample Number must exist in the Biota Sample table.

Related Sample Number must exist in the Biota Sample table.

Sample Site ID must exist in the Sampling Site table. 
Section

Page

Date
2.3 .1

2 of 4

$01 / 14 / 94$

Figure 2.3.1-1. Biota Sample Form.

Biota Sample

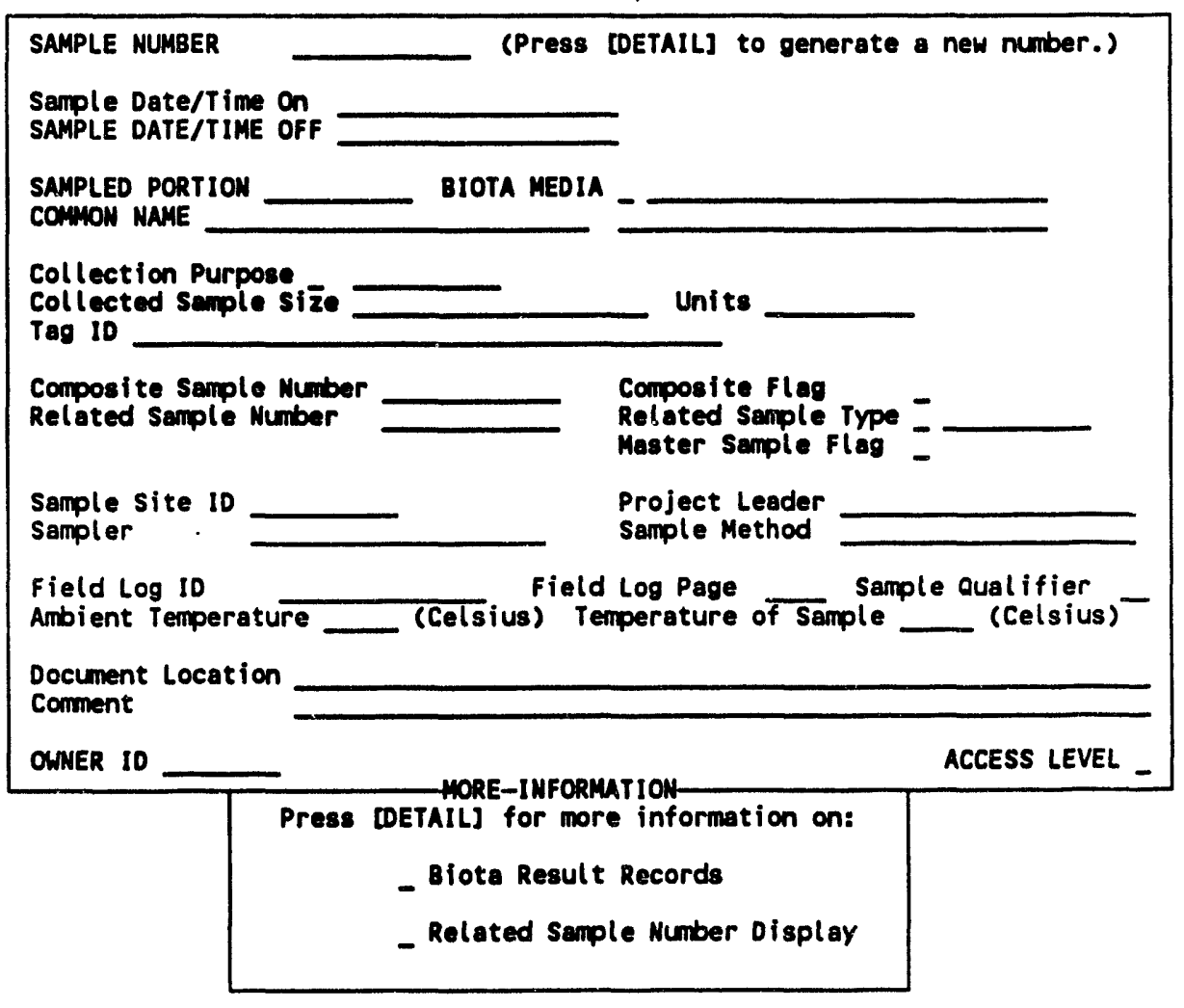

Special Processing

If Sample Number does not exist in the Sample table, press [DETAIL] to generate a new one (not available in browser mode).

Processing the Related Sample Number and Composite Sample Number fields is described in Section 4.3.3 of the HEIS User's Guide (DOE-RL 1994a).

Code Lookup/

Validation

Biota Media

Collected Sample Size Units

Collection Purpose

Common Name

Related Sample Type

Sample Method

Sample Qualifier

Sample Site ID

Sampled Portion 


\author{
Required Fields Biota Media \\ Common Name \\ Sample Date/Time Off \\ Sample Number* \\ Sampled Portion \\ Recommended Query \\ Choice 1 - Sample Number \\ Fields \\ Choice 2 - Sampled Portion \\ Choice 3 - Sample Date/Time Off \\ Choice 4 - Common Name \\ Choice 5 - Sample Site ID
}

FORM FIELD NAMES/ DATTABASE FIELD NAMES
Form Field Name

Ambient Temperature

Biota Media

Collected Sample size

Collected Semple size Units

Collection Purpose

Comment

Common Nane

Composite Flag

Composite Sample Number

Document Location

Field Log ID

Field Log Page

Master Sample Flag

Project Leader

Related Sample Number

Related Sample Type

Sample Date/Time On

Sample Date/Time off

Sample Method

Sample Number

Sample Qualifier

- Sample site ID

Sampled Portion

Sampler

Tag 10

Temperature of Sample
Database Field Name

ambient_temp

biota_media

coll_samp_size

coll samp size units

collection purpose

samp_corment

common name

composite_flag

composite_samp_num

doc 100

fietd $\log _{\text {id }}$

field_logjpage

master samp flag

project lead

related_samp_num

related_samp_type

samp date time on

samp_date-time_off

samp_mthd

semp num

samp_qual

samp_site_id

sampted portion

sampler

tag_id

temp_of_samp 
$\begin{array}{lr}\text { Section } & 2.3 .1 \\ \text { Page } & 4 \text { of } 4\end{array}$

Date $01 / 14 / 94$
DOE/RL-93-24-5

This page intentionally left blank. 


\subsubsection{BIOTA RESULT TABLES}

\subsubsection{Biota Result Table \\ (HEIS Database Table Name: biota_result)}

INTRODUCTION

The Biota Result table contains the results of laboratory analyses performed on biota samples. Some properties of the samples, such as $\mathrm{pH}$, temperature, and conductivity, are also stored in this table. Each record contains a result and associated data for a particular constituent for a sample.

There are two ways to access Biota Result data depending on whether you want the form to display selected fields for multiple records or all fields for a single record.

- The Biota Result form is shown in Figure 2.3.2.1-1. To access this form, choose the "Biota Result" option on the Biota Subject Area menu.

- The Biota Result Multiple View form is shown in Figure 2.3.2.1-2. This form allows you to view five result records at a time. To access this form, choose the "Biota Result - Multiple" option on the Biota Subject Area menu.

This is a view-only form. Its purpose is to allow you to compare several selected records. To improve the performance of this form, there is no code lookup available for the Lab code field.

SOURCE

The source of the data is usually the laboratory where the analysis was performed. These results are typically received electronically. This table can also contain data collected in the field concerning properties of the samples. 
Section

Page

Date
2.3 .2 .1

2 of 6

$01 / 14 / 94$

Figure 2.3.2.1-1. Biota Result Form.

Biota Result

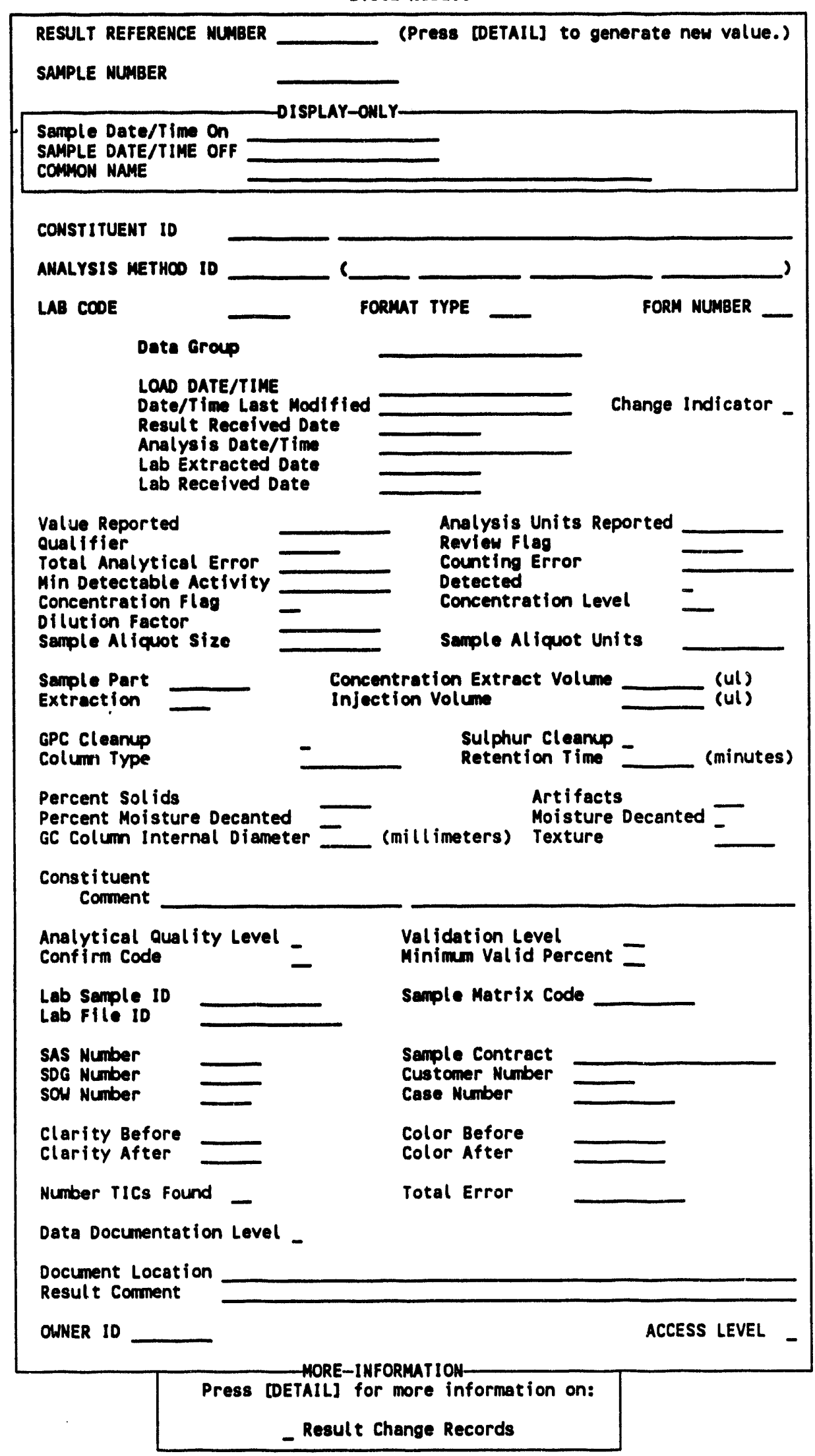


Figure 2.3.2.1-2. Biota Result Multiple View Form.

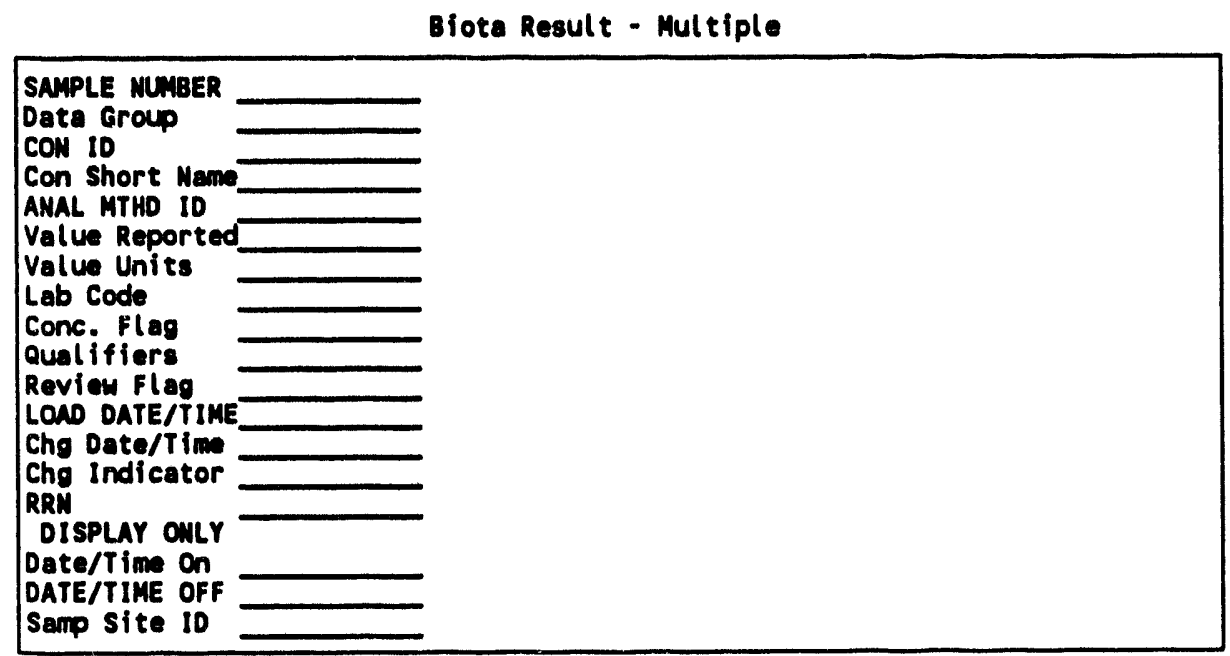

\section{REQUIREMENTS}

\section{Dependencies}

\section{Special Processing}

Analysis Method ID must exist in the Analysis Method table.

Constituent Comment and Lab code must exist as a pair in the Comments table.

Constituent ID must exist in the Constituent table.

The Constituent ID and Analysis Method ID pairing must exist in the Constituent code table.

Lab Code must exist in the Laboratory table.

Sample Number must exist in the Biota Sample table.

A Biota Change record is generated when a Biota Result record is modified or deleted (see Section 4.3.5 of the HEIS User's Guide [DOE-RL 1994a] for a detailed description).

The following fields are assigned by the system and are for query only:

Change Indicator Date/Time Last Modified Load Date/Time Result Reference Number 
Section

Page

Date

2.3.2.1

4 of 6

$01 / 14 / 94$

The following fields are for display only:

Common Name

Sample Date/Time off

Sample Date/Time On

Pressing [DETAIL] in the Sample Number field brings up the associated Biota Sample record in browser mode.

Instructions for the following are found in Section 4.3.4 of the HEIS User's Guide:

- Date restrictions

- Fields displayed in scientific notation

- The relationship between Form Number and Format Type

- Processing the Constituent Comment, Qualifier, and Review Flag fields.

Code Lookup/ Validation
Analytical Quality Level

Analys is Method ID

Analys is Units Reported

Column Type

Concentration Flag

Concentration Level

Confirm Code

Constituent Comment

Constituent ID

Data Documentation Level

Extraction

Form Number

Format Type

Lab Code (not available on multiple view form)

Qual ifiers

Review Flag

Sample Aliquot Units

Sample Matrix Code

Sample Part

Texture

Validation Level 


\section{Required Fields}

Recommended Query Fields
Analysis Method ID

Common Name

Constituent ID

Form Number

Format Type

Lab Code

Load Date/Time

Result Reference Number*

Sample Date/Time off

Sample Number

Choice 1 - Result Reference Number

Choice 2 - Sample Number Constituent ID

Analysis Method ID

Lab Code

Format Type

Form Number

Choice 3 - Constituent ID

Choice 4 - Data Group

Load Date/Time 
FORM FIELD NAMES DATABASE FIELD NAMES
Form field Neme

Analytical Quality Level

Anstysis Date/Time

Analysis Mothod ID

Artifacts

Analysis Units Reported

Case Number

Change Indicator

Clarity After

Clarity Before

Color After

Color Before

Column Type

Common Name

Concentration Extract Volume

Concentration Flag

Concentration Level

Confirm Code

Constituent Comment

Constituent ID

Counting Error

Customer Number

Data Documentation Level

Data Group

Date/Time Last Modified

Detected

Dilution Factor

Document Location

Extraction

Form Number

Format Type

GC Colum Internal Diameter

GPC Cleanup

injection volume

Lab code

Lab Extracted Date

Lab File ID

Lab Received Date

Lab sample ID

Load Date/Time

Min Detectable Activity

Minimum Valid Percent

Moisture Decanted

Number Tics Found

Percent Moisture Decanted

Percent Solids

Qualifiers

Result Corment

Result Received Date

Result Reference Number

Retention Time

Review Flag

Sample Aliquot Size

Sample Al iquot Units

Semple Contract

Sample Date/Time on

Sample Date/Time off

Semple Filtered

Sample Matrix Code

Sample Number

Sample Part

SAS Number

SDG Number

SOW Number

Sulphur Cleanup

Texture

Total Analytical Error

Total Error

Validation Level

Value Reported
Database Field Name

aql

anal_date time

anal mthd id

artifacts

anal_units_rptd

case num

change indicator

clarity. after

clarity before

color after

color_before

column type

common name

conc_extract_vol

conc_flag

conc level

confTrm_code

con_comment

con id

count ing error

cus tomer_num

data documentation level

data_group

date_last_modified

detected

dilut factor

doc_loc

extraction

form num

format_type

gc_colüm_id

gpe clean up

injection_vol

lab_code

lab_extracted_date

lab file id

lab_received_date

lab samp id

losd date time

min_detectable_activity

min valid pent

moisture dec

num tics found

pent_moisture_dec

pent solids

qualiffier

result_comment

result_received_date

rrn

retention_time

review flag

semp_atiquot size

semp_al iquot_units

samp contract

samp date time on

samp_date_t ime_off

samp fil tered

samp matrix_code

samp_num

samp part

sas_num

sdg_num

sownum

sulphur_cleanup

texture

total_anal_error

total error

validātion level

value_rptd 


\title{
2.3.2.2 Biota Result Change Table
}

\author{
(HEIS Database Table Names: biota_result_change)
}

INTRODUCTION

SOURCE

REQUIREMENTS

Code Lookup/

Validation

Required Fields
The Biota Result Change table contains a time-stamped historical record of changes made to biota result records. Some aspects of the sample results, such as value reported and qualifiers, are subject to change. The reason for the change, the change authority and user name, the change code, and the date/time of change also are stored. The Biota Change View form is shown in Figure 2.3.2.2-1 provides a was to view this historical record. To access this form, choose the "Biota Change View" option from the Biota Subject Area menu.

The source of the data is a previous record in the Biota Result table. These records are generated automatically when a result record is modified or deleted. See Section 4.3.5 of the HEIS User's Guide (DOE-RL 1994a).

"Dependencies" and "Special Processing," are the same as found in the Biota Result table (see Section 2.3.2.1). The "Required Fields," "Code Lookup/Validation" and "Form Field Name/Database Field Name" lists are the same with the exception of specific changes listed in the sections below. A complete description of the change record generation process is found in Section 4.3 .5 of the HEIS User's Guide.

All fields in the Biota Result table plus Change Code

All fields in the Biota Result table plus Change Authority

Change Code

Change User Name

Change Reason 


$\begin{array}{lr}\text { Section } & 2.3 .2 .2 \\ \text { Page } & 2 \text { of } 4 \\ \text { Date } & 01 / 14 / 94\end{array}$

Recommended Query Fields
Choice 1 - Result Reference Number Change Date/Time

Choice 2 - Sample Number

Constituent ID

Analys is Method ID

Lab Code

Format Type

Form Number

Change Date/Time

All fields in the Biota Result table plus -

FORM FIELD NAMES/

DATABASE FIELD NAMES
Form field Name

Change Authority

Change Code

Change Date/T ime

Change Reason

Change User Nene
Database Field Name change_authority

change code

change date time

change_reason

change_user_neme 
Figure 2.3.2.2-1. Biota Result Change View Form. Biota Result Change View

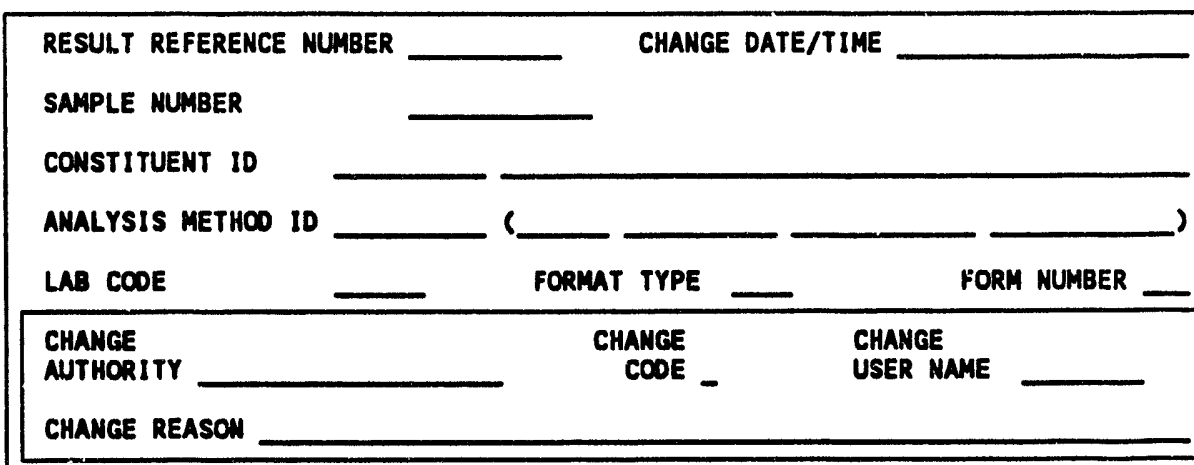

Data Group

LOAD DATE/TIME

Date/Time Last Modified

Result Received Date

Analysis Date/Time

Lab Extracted Date

Lab Received Date

Value Reported

Qualifiers

Total Analytical Error

Min Detectable Activity

Concentration Flag

Dilution Factor

Sample Al iquot size

Sample Part
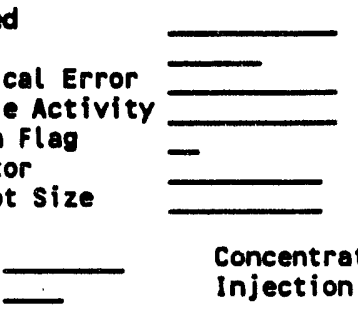

Analysis Units Reported

Review Flag

Counting Error

Detected

Concentration Level

Sample Aliquot Units

Extraction

Concentration Extract Volume

Injection volume

Change Indicator -

GPC Cleanup

Colum Type

$-$

Sulphur Cleanup

Percent Solids

Percent Moisture Decanted

GC Column Internal Diameter

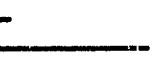

Retention Time

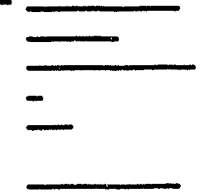

(ul)

(ul)

Const i tuent
Comment

Analytical ouality Level -

Confirm Code

Lab Sample ID

Lab file ID

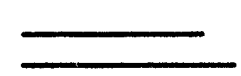

SAS Number

SDG Number

sow Number

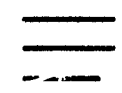

Clarity Before

Clarity After

Number rics found

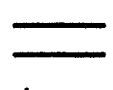

$-$

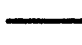
(millimeters)

Artifacts

Moisture Decanted -

Texture (minutes)

Data Documentation Level -

Document Location

Result Comment

OWNER ID

Validation Level

Minimum Valid Percent -

Sample Matrix Code

Sample Contract

Customer Number

Case Number

Color Before

Color After

Total Error

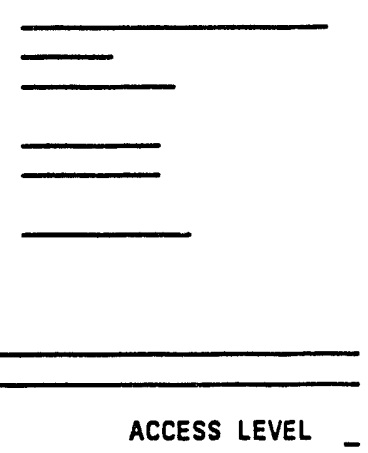




$$
\text { Section 2.3.2.2 DOE/RL-93-24-5 }
$$

This page intentionally left blank. 


\subsubsection{BIOTA POPULATION TABLE}

(HEIS Database Table Name: biota_population)

\section{INTRODUCTION}

SOURCE

\section{REQUIREMENTS}

Dependencies

Special Processing

Code Lookup/

Validation

Required Fields

Recommended Query Fields
The Biota Population table contains data from population studies. The table contains the count of organisms, the units associated with the count, a description, and a sample number. The associated Biota Sample record contains the identification of the organism counted, the dates of study, the station where the sample was collected, and other descriptive information. The Biota Population form is shown in Figure 2.3.3-1.

Figure 2.3.3-1. Biota Population Form. Biota Population

\begin{tabular}{|r|r|}
\hline SAMPLE NUMBER & \\
UNITS REPORTED & \\
DESCription & ACCESS LEVEL - \\
OWNER ID & \\
\hline
\end{tabular}

Data for this table come from the biologist who conducted the population study.

Sample Number must exist in the Biota Sample table.

None.

Units Reported

Count

Sample Number*

Units Reported

Choice 1 - Sample Number 
Section

Page

Date

2.3 .3 2 of 2 $01 / 14 / 94$

FORM FIELD NAMES/ DATABASE FIELD NAMES
DOE/RL-93-24-5

Database Field Name

biote_pop_count

biote_pop_desc

samp_num

anal_units_rptd

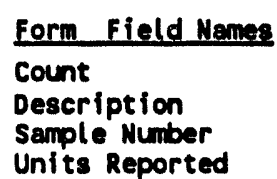

Form Field Nemes

Units Reported

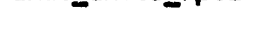




\subsubsection{BIOTA DISTRIBUTION TABLE}

(HEIS Database Table Name: biota_distribution)

INTRODUCTION

SOURCE

\section{REQUIREMENTS}

Dependencies

Special Processing

Code Lookup/

Validation

Required Fields
The Biota Distribution table contains information about the map generated to depict the results of a distribution study. The associated Biota Sample record contains the identification of the organism mapped, the dates of study, the station where the sample was collected, and other descriptive information. The Biota Distribution form is shown in Figure 2.3.4-1.

The Biota Distribution table contains a GIS map ID for this map and a description of the study. Currently, the map cannot be stored in the HEIS GIS. The Description field is used to note the location of the distribution map. In the future, the distribution map, known as an overlay, will be stored in the HEIS GIS.

Figure 2.3.4-1. Biota Distribution Form.

Biota Distribution

SAMPLE NUABER

GIS Map ID

Description

OWNER IO

ACCESS LEVEL

Data for this table come from the biologist who conducted the distribution study.

Sample Number must exist in the Biota Sample table.

None.

None.

Sample Number* 


\begin{tabular}{|c|c|c|}
\hline $\begin{array}{l}\text { Section } \\
\text { Page } \\
\text { Date }\end{array}$ & $\begin{array}{r}2.3 .4 \\
2 \text { of } 2 \\
01 / 14 / 94\end{array}$ & DOE/RL-93-24-5 \\
\hline
\end{tabular}

Recommended Query Choice 1 - Sample Number Fields

FORM FIELD NAMES/

DATABASE FIELD NAMES
Eorm Field Nemes

Description

GIS Map ID

Sample Number
Database Field Neme

biota_dist_desc

gis_map_id 


\subsubsection{BIOTA SPECIES TABLE}

(HEIS Database Table Name: biota_species)

INTRODUCTION

SOURCE

Dependencies

Special Processing

Code Lookup/

Validation

Required Fields

Recommended Query
The Biota Species table contains the names for organisms that have been or might become a biota sample. The Common Name is the generic name used to describe the organism. If the name is intended to describe more than one species of organism, the plural of the name should be used. For example, to describe multiple species of duck, the Common Name should be "DUCKS."

Species refers to the latin binomial for an organism. The unique identifier for the Biota Species table is Common Name. This means that only one record may be identified with the Common Name "DUCK." For a duck with species " $X$ " and another duck with species "Y," the common names for each of these records must be different. The Biota Species form is shown in Figure 2.3.5-1.

Figure 2.3.5-1. Biota Species Form.

Biota Species

\begin{tabular}{|l} 
COMMON MAME \\
\hline
\end{tabular}

Data for this table come from a biologist.

None.

This form allows multiple records to be viewed and inserted at one time.

Species

Common Name*

Choice 1 - Common Name 
Section 2.3.5 COE/RL-93-24-5

Page 2 of 2

Date $\quad 01 / 14 / 94$

Fields

FORM FIELD NAMES/

DATABASE FIELD NAMES

Eorm Fild Nem

Common Nawe

Spectes
Detrabere Fileld Hens

comion_neme

species 
DOE/RL-93-24-5

Section $\quad 2.3 .6$

Page 1 of 2

Date $01 / 14 / 94$

\subsubsection{BIOTA REPORTING GROUP TABLE}

To be issued. 
Section 2.3 .6

Page

2 of 2

DOE/RL-93-24-5

Date

$01 / 14 / 94$

This page intentionally left blank. 


\subsection{THE SURFACE WATER SUBJECT AREA}

\subsection{OVERVIEW}

PURPOSE

SCOPE

DATA MODEL
The purpose of the HEIS Surface Water subject area is to manage the data acquired from surface water samples. Data stored in the Surface water subject area include data relevant to the surface water samples, laboratory analytical results as well as field measurements.

Two major types of data make up the Surface Water subject area.

- Data about the samples--These are samples that are sent to a laboratory for analysis. Characteristics concerning the sample itself are stored in the SW Sample table.

- Data about the chemical and/or radiologic analyses of surface water samples--These types of samples can be analyzed using a variety of protocols. The results of all types of analyses are stored in the SW Result table.

Figure $3 \cdot 1-1$ is a data model showing relationships among the tables in the Surface Water subject area and their relationships with other HEIS tables. The associations are described below. Capitalized items refer to both the actual item and the Surface Water table in which data about that item are stored.

Each SW Sample record has many SW Result records.

Each result record represents the measurement of a specified constituent for this sample. Each SW Sample record may have one or more SW Result Change records associated with it. The change records are created automatically when a corresponding result record is modified. 
Section

Page

Date

Figure 3.1-1. Data Model Showing Relationships Among the Tables in the Surface Water Subject Area and Their Relationships with Tables Located in Other HEIS Subject Areas.

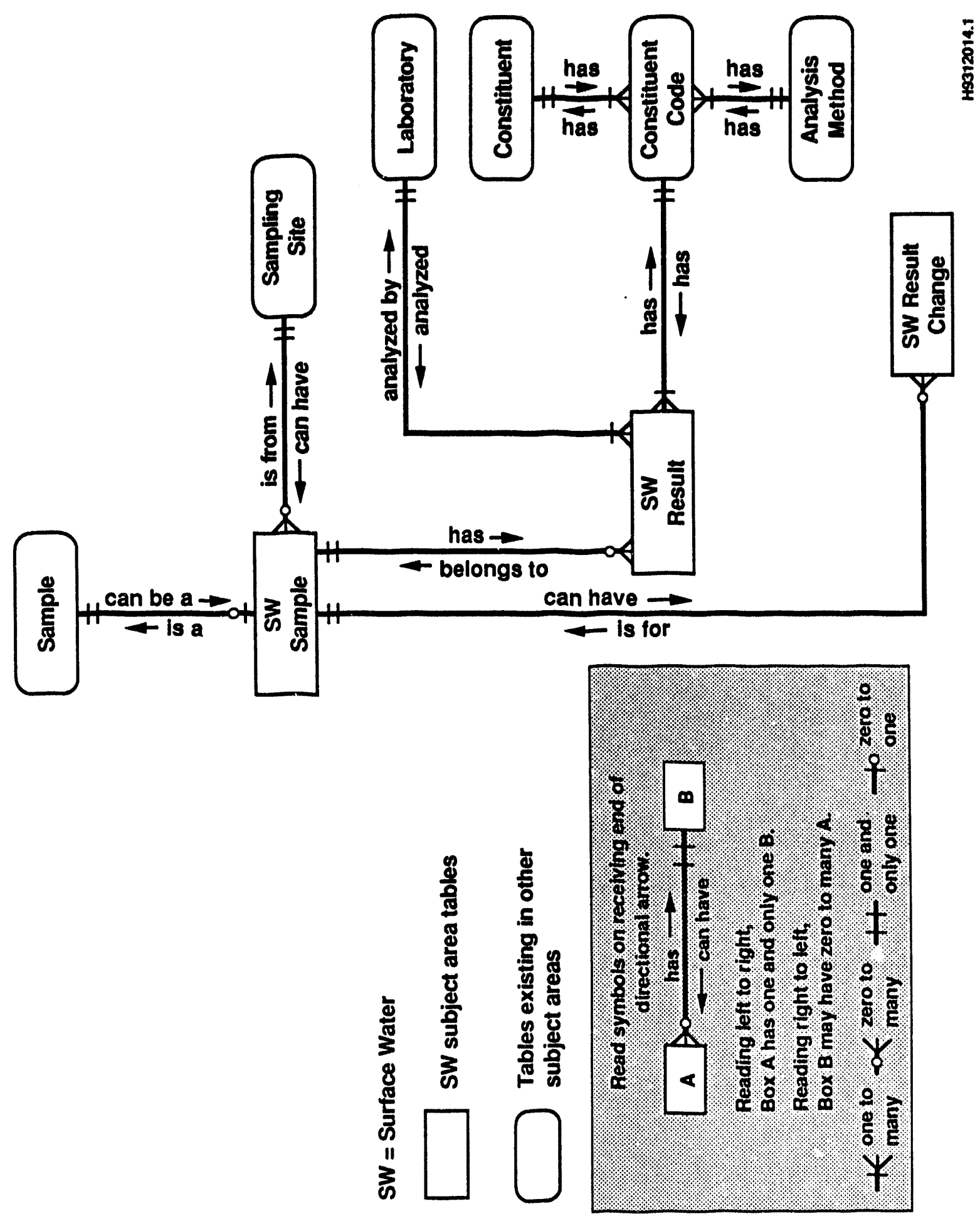

$\frac{5}{8}$ 
USERS

MENU SYSTEM
The users of the Surface Water subject area include (1) technical staff interested in data related to surface water, (2) technical staff interested in any contamination found when the samples are analyzed for the presence of various constituents, (3) data processing staff responsible for inserting and maintaining the surface water data, and (4) technical staff at regulatory agencies interested in monitoring the levels of various contaminants found in the samples.

The Surface Water subject area allows you to navigate among the Surface Water forms using the HEIS query-byform interface. Section 3.1 describes how to access the various Surface Water forms using this interface. The Surface Water tables are described in Section 3.2 
迸

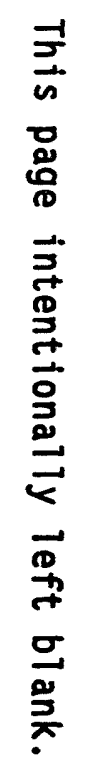

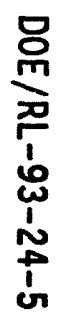




\subsection{ACCESSING SURFACE WATER DATA}

INTRODUCTION

The Surface Water menu, presented in Figure 3.2-1, shows the entry points into the Surface Water forms. Figure 3.2-2 is a diagram of how these forms and other forms are connected. See Section 5.3 of the HEIS User's Guide (DOE-RL 1994a) for a detailed description of entry point maps. Section 3.3 describes each of the tabies and forms associated with individual entry points.

Figure 3.2-1. Surface Water Menu.

HANFORD ENVIRONMENTAL INFORMATION SYSTEM Surface Water Subject Area MENULOPTIONS

SW Sample

SH Result

SW Result - Multiple
SW Result Change Update

SW Result Change View 
Section

Page

Date
3.2

2 of 2

$01 / 14 / 94$

Figure 3.2-2. Map of Surface Water Entry Points.

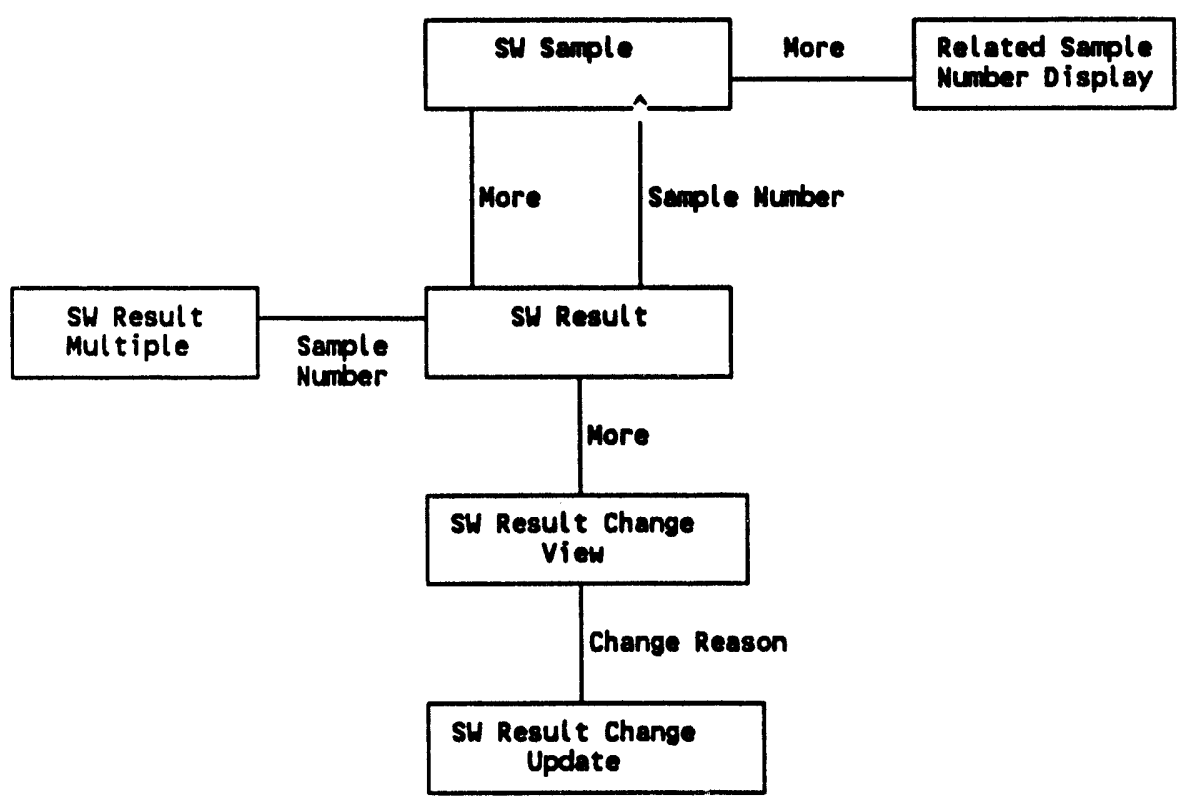




\subsection{THE SURFACE WATER TABLES}

\subsubsection{SW SAMPLE TABLE}

(HEIS Database Table Name: SW_sample)

INTRODUCTION

Figure 3.3.1-1. SW Sample Form.

The SW Sample table contains data concerning water samples taken from sources located on the land, such as, rivers, lakes, or ponds. The data are supplied by the sampler from field tests and evaluations. Each surface water sample is uniquely identified by a sample number. Other important data are the sample type and the date of sampling. The SW Sample form is shown in Figure 3.3.1-1.

SH Semple

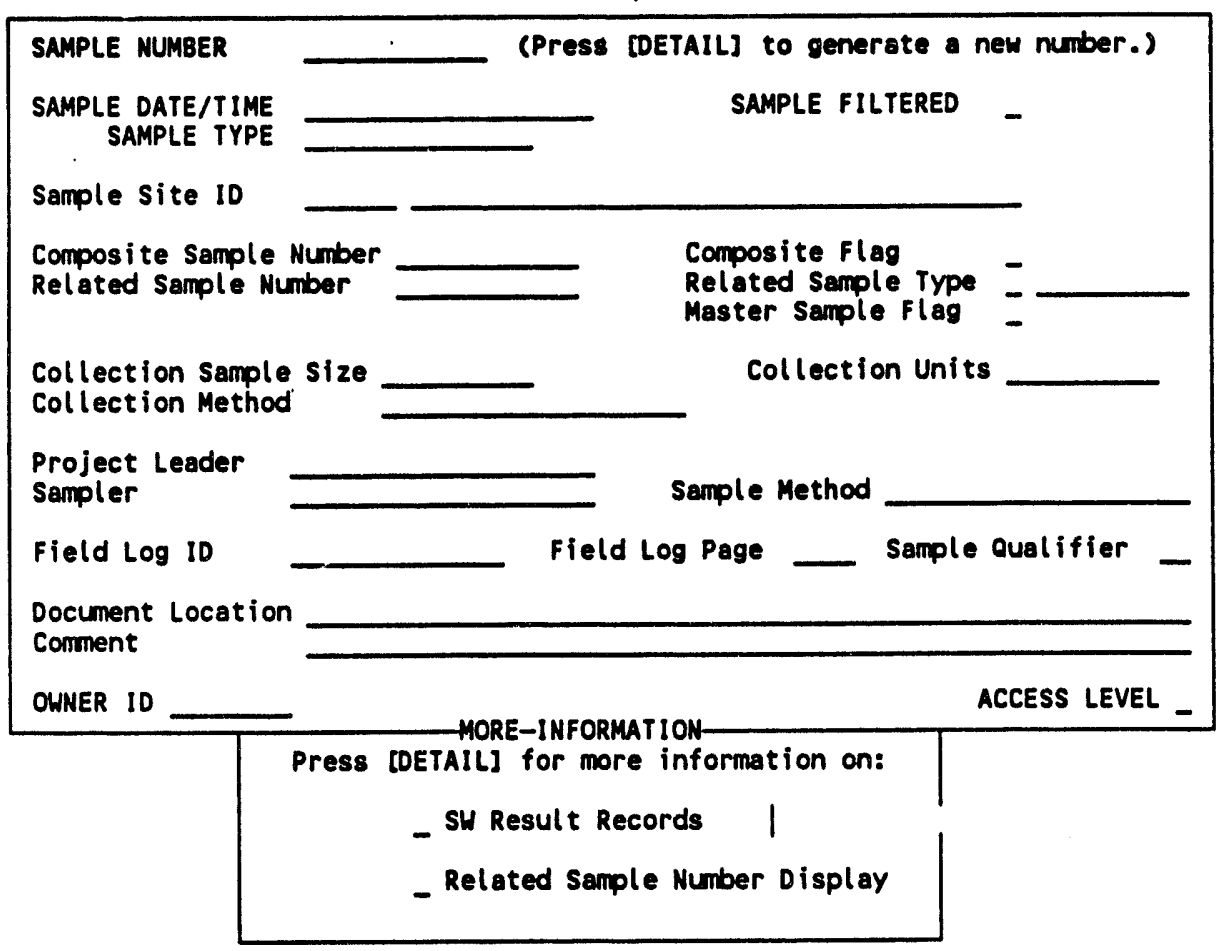

SOURCE

Data for this table come from field log books, which are filled out during sampling. 
Section

Page 3.3 .1

Date 2 of 4 $01 / 14 / 94$

\section{REQUIREMENTS}

Dependencies

Special Processing

Code Lookup/

Validation

Required Fields

Recommended Query Fields
Related Sample Number must exist in the SW Sample table.

Composite Sample Number must exist in the SW Sample table.

Sample Site ID must exist in the Sampling Site table.

If Sample Number does not exist in the Sample table, press [DETAIL] to generate a new one (not available in browser mode).

Processing the Related Sample Number and Composite Sample Number fields is described in Section 4.3 .3 of the HEIS User's Guide (DOE-RL 1994a).

Sample Date/Time and Sample Filtered for an existing record cannot be modified using this form.

Collection Method

Collection Units

Related Sample Type

Sample Method

Sample Qualifier

Sample Site ID

Sample Type

Sample Date/Time

Sample Filtered

Sample Number*

Sample Type

Choice 1 - Sample Number

Choice 2 - Sample Date Time 
FORM FIELD NAMES/ DATABASE FIELD NAMES
Form Field Mans

Collection Method

Collection semple size

Collection Units

Comment

Composite Flas

Composite Semple Number

Document Location

Field Log ID

Field Log Page

Master Semple Flag

Project Leader

Related Semple Number

Related Sample Typo

Sample Date/Time

Sample Filtered

Sample Method

Sample Number

Sample Qualifier

Sample site ID

Sample Type

Sampler
Database Fielo Name

coll_mthd

coll_samp_size

coll_samp_size_units

semp comment

composite fleg

composite_semp_num

doc loc

fietd log id

field log page

master_semp_flag

project lead

related_samp_num

related_samp_type

semp date time

sampTe fittered

semp_mthd

samp_num

samp_qual

samp_site_id

samp type

sampTer 
Date $01 / 14 / 94$

This page intentionally left blank. 


\subsubsection{SW RESULT TABLES}

\subsubsection{SW Result Table}

(HEIS Database Table Name: sw_result)

INTRODUCTION

SOURCE
The SW Result table contains the results of laboratory analyses performed on surface water samples. Some properties of the samples, such as $\mathrm{pH}$, temperature, and conductivity, also are stored in this table. Each record contains a result and associated data for a particular constituent for a sample.

There are two ways to access SW Result data depending on whether you want the form to display selected fields for multiple records or all fields for a single record.

- The SW Result form is shown in Figure 3.3.2.1-1. To access this form, choose the "SW Result" option on the Surface Water Subject Area menu.

- The SW Result Multiple View form, shown in Figure 3.3.2.1-2, allows you to view five result records at one time. To access this form, choose the "SW Result - Multiple" option on the Surface Water Subject Area menu.

This is a view-only form. Its purpose is to allow you to compare several selected records. To improve the performance of this form, there is no code lookup available for the Lab Code field.

The source of the data is usually the laboratory where the analysis was performed. Typically these results are received electronically. This table also can contain data collected in the field concerning properties of the samples. 
Section

Page

3.3.2.1

2 of 6

Date $01 / 14 / 94$

Figure 3.3.2.1-1. SW Result Form.

SW Result

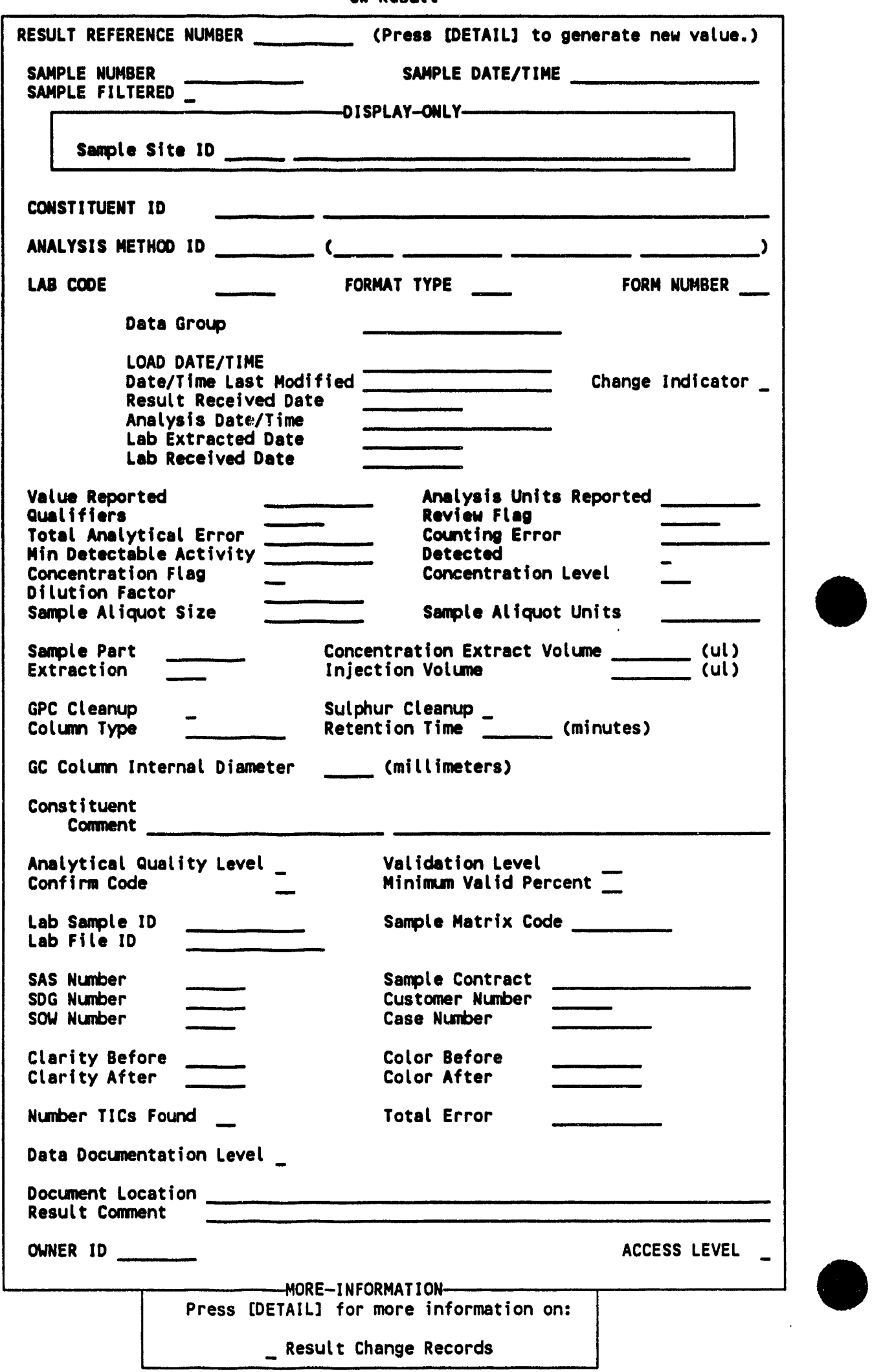


Figure 3.3.2.1-2. SW Result Multiple View Form. Surface-Hater Result -Multiple

\begin{tabular}{l}
\hline SAMPLE NUMAER \\
Data Group \\
SAMP DATE/TIME \\
CON ID \\
Con Short Neme \\
ANAL MTHD ID \\
Value Reported \\
Valu Units \\
Lab Code \\
Conc. Flag \\
Qual ifiers \\
Review Flag \\
SAMPLE FILTER \\
LOAD DATE/TIME \\
Chg Date/T Ime \\
Chg Indicator \\
RRN
\end{tabular}

\section{REQUIREMENTS}

Dependencies

Analysis Method ID must exist in the Analysis Method table.

Constituent Comment must exist in the Comments table.

Constituent ID must exist in the Constituent table.

The Constituent ID and Analysis Method ID pairing must exist in the Constituent code table.

Lab Code must exist in the Laboratory table.

Sample Number must exist in the SW Sample table.

Special Processing

A SW Result Change record is generated when a SW Result record is modified or deleted (see Section 4.3.5 of the HEIS User's Guide [DOE-RL 1994a] for a detailed description).

The following fields are assigned by the system and are for query only:

Change Indicator

Date/Time Last Modified Load Date/Time

Result Reference Number

Sample Date/Time

Sample Filtered 
Section

Page

Date

3.3 .2 .1

4 of 6

$01 / 14 / 94$
Code Lookup/

Validation

Required Fields
DOE/RL-93-24-5

Pressing [DETAIL] in the Sample Number field brings up the associated SW Sample record in browser mode.

Instructions for the following are found in Section 4.3 .4 of the HEIS User's Guide:

- Date restrictions

- Fields displayed in scientific notation

- The relationship between Form Number and Format Type

- Processing the Constituent Comment, Qualifier, and Review Flag fields.

Analytical Quality Level

Analys is Method ID

Analys is Units Reported

Column Type

Concentration Flag

Concentration Level

Confirm Code

Constituent Comment

Constituent ID

Data Documentation Level

Extraction

Form Number

Format Type

Lab Code (not available on multiple view form)

Qualifiers

Review Flag

Sample Aliquot Units

Sample Matrix Code

Sample Part

Validation Level

Analys is Method ID

Constituent ID

Form Number

Format Type

Lab Code

Load Date/Time

Result Reference Number*

Sample Date/Time

Sample Filtered

Sample Number 
Recommended Query Fields
Choice 1 - Result Reference Number

Choice 2 - Sample Number Constituent ID

Analysis Method ID

Lab Code

Format Type

Form Number

Choice 3 - Data Group Load Date/Time

Choice 4 - Sample Date/Time 
FORM FIELD MAMES/ DATABASE FIELD NAMES
Eom field Hem

Analytical quality Level

Analysis Date/Time Analyais Method ID Analysis Units Reported

Case Number

Chenge Indicetor

Clarity After

Clarity Bafore

Color After

Color Before

Colum Type

Concentration Extrect Volum

Concentration Flag

Concentration Level

Confirm cods

Const ituent Combent

Constituent 10

Counting Error

Customer Number

Data Documentation Level

Data Group

Date/Time Last Modified

Detected

Dilution Factor

Document Location

Extraction

Form Number

Format Type

GC Colum internal Diconter

GPC Cleanup

Injection volum

Lab Code

Lab Extracted Date

Lab file ID

Lab Received Date

Lab Semple ID

Load Date/Time

Min Detectable Activity

Minimum Valid Percent

Number TICs found

Qualifiers

Result Comment

Result Received Date

Result Reference Number

Retention Time

Revien Flag

Sample Allavot size

Sample Al iquot Units

Sample Contract

Sample Date/Time

Semple Filtered

Sample Matrix Code

Sample Number

Sample Part

SAS Number

SDG Number

sow Number

sulphur Cleanup

Total Analytical Error

Total Error

Validation Level

Value Reported
Datubase Fleld Neme

eql

anal date time

anal_mthd_id

anal-units_rptd

case num

change_indicator

ctarity after

clarity before

color_after

color before

columñ type

conc_extract_vol

conc-flag

conc level

conf Trm_code

con comment

con id

counting_error

customer_num

data documentation level

data-group

date_last_modified

detected

dilut_factor

doc_loc

extraction

form $\mathrm{mum}$

formint type

ge colum id

opéclean_up

injection_vol

lab_code

lab-extracted date

lab_ile id

lab received_date

lab samp id

load_date_time

min detectable activity

min valid pent

num_tics found

quatifier

result comment

resul $t$ _received_date

rrn

retention time

review fläg

semp at iquot size

samp al iquot units

semp_contract

sampdate time

semp-filtéred

samp_matrix_code

samp_num

samp part

sas_num

sdg_num

sow num

sulphur cleanup

total añal error

total error

validätion level

value_rptd 


\title{
3.3.2.2 SW Result Change Tables
}

\author{
(HEIS Database Table Names: sw_result_change)
}

INTRODUCTION

SOURCE

\section{REQUIREMENTS}

Code Lookup/

Validation

Required Fields
The SW Result Change table contains a time-stamped historical record of changes made to surface water result records. Some aspects of the sample results, such as value reported and qualifiers, are subject to change. The reason for the change, the change authority and user name, the change code, and the date/time of change also are stored. The SW Result Change View form shown in Figure 3.3.2.2-1 provides a way to view this historical record. To access this form, choose the "SW Result Change View" option on the Surface Water Subject Area menu.

The source of the data is a previous record in the SW Result table. These records are generated automatically when a result record is modified or deleted. See Section 4.3.5 of the HEIS User's Guide (DOE-RL 1994a) for details.

"Dependencies" and "Special Processing," are the same as found in the SW Result table (see Section 3.3.2.1). The "Required Fields," "Code Lookup/Validation" and "Form Field Name/Database Field Name" 1ists are the same with the exception of specific changes listed in the sections below. A complete description of the change record generation process is found in Section 4.3.5 of the HEIS User's Guide.

All fields in the SW Result table plus Change Code

All fields in the SW Result table plus -

Change Authority

Change Code

Change User Name

Change Reason 
Section

Page

Date
3.3 .2 .2

2 of 4

$01 / 14 / 94$

Figure 3.3.2.2-1. SW Result Change View Form.

SW Result Change View

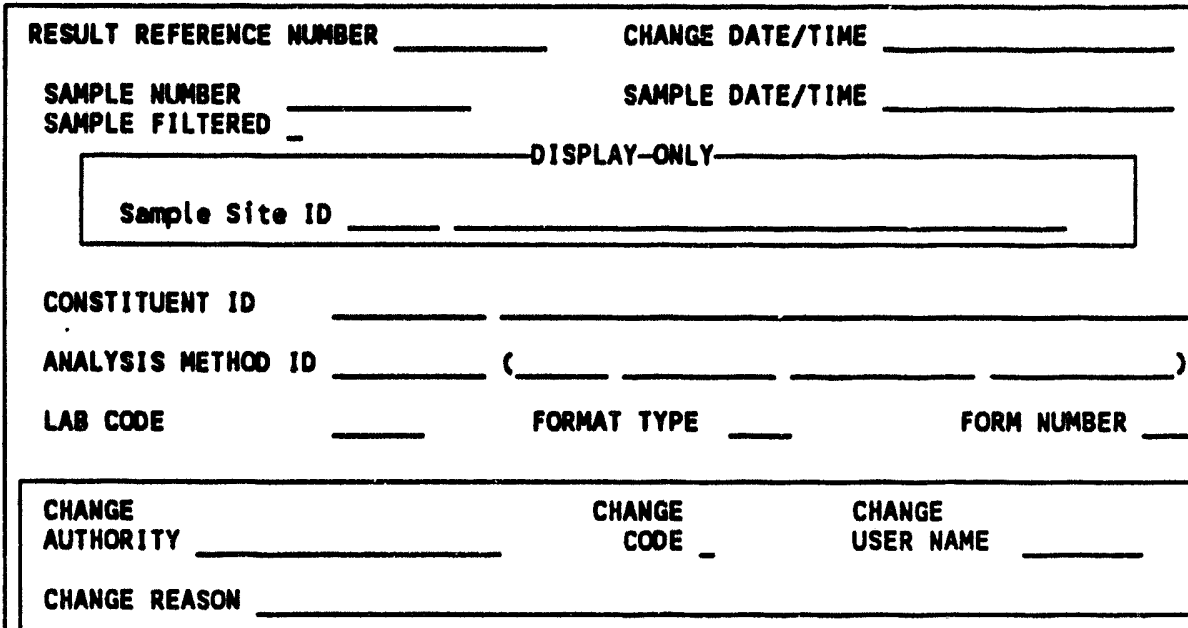

\section{Data Group \\ LOAD DATE/TIME \\ Date/Time Last Modified \\ Result Received Date \\ Analysis Date/Time \\ Lab Extracted Date \\ Lab Received Date}

Value Reported

Qualifiers

Total Analytical Error

Min Detectable Activity

Concentration Flag

Dilution Factor

Sample Al iquot size

Sample Part

Extraction

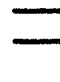

GPC Cleanup

Colum Type
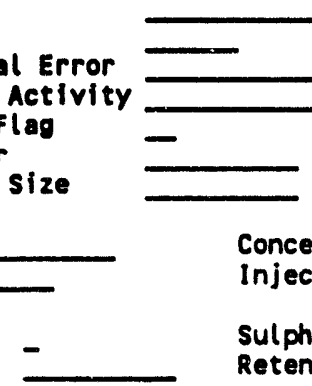

Analysis Units Reported

Review Flag

Counting Error

Detected

Concentration Level

Sample Al iquot Units

Concentration Extract Volume Injection Volume

(uL)

Sulphur cleanup

Retention Time (minutes)

GC Column Internal Diameter

(millimeters)

Const i tuent

Conment

Analytical ouality Level

Confirm Code

Validation Level

Minimum Valid Percent -

Lab Sample 10

Lab File ID

Sample Matrix Code

SAS Number

SOG Number

sow Number

Clarity Before

Clarity After

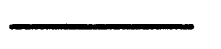

Sample Contract

Customer Number

Case Number

Color Before

Color After

Number TICs found

Total Error

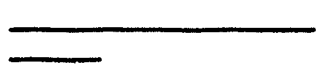

Data Documentation Level

Document Location

Result Comment

OWNER ID

ACCESS LEVEL 
Recommended Query Fields

FORM FIELD NAMES/ DATABASE FIELD NAMES
Choice 1 - Result Reference Number Change Date/Time

Choice 2 - Sample Number Constituent ID Anaiys is Method ID Lab Code

Format Type

Form Number

Change Date/Time

All fields in the SW Result table plus -

$$
\begin{aligned}
& \text { Form Field Name } \\
& \text { Change Authority } \\
& \text { Change Code } \\
& \text { Change Date/Time } \\
& \text { Change Reason } \\
& \text { Change User Name }
\end{aligned}
$$

Database Fleld Name

change_authority

change code

change date time

change_reason

change-user_name 
Section 3.3.2.2

Page

Date

4 of 4 $01 / 14 / 94$
DOE/RL-93-24-5

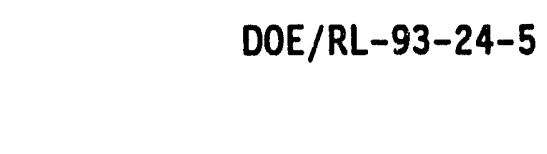

This page intentionally left blank. 


$$
\text { DOE/RL-93-24-5 }
$$$$
\begin{array}{lr}
\text { Section } & 4.0 \\
\text { Page } & 1 \text { of } 2 \\
\text { Date } & 01 / 14 / 94
\end{array}
$$

4.0 THE RIVER CHARACTERISTICS SUBJECT AREA

To be issued. 
Section 4.0

Page 2 of 2

Date $01 / 14 / 94$
DOE/RL-93-24-5

This page intentionally left blank. 


\section{REFERENCES}

\section{HEIS MANUALS}

DOE-RL, 1994a, Hanford Environmental Information System (HEIS): Volume 1 User's Guide, DOE/RL-93-24-1, U.S. Department of Energy, Richland Operations Office, Richland, WA.

DOE-RL, 1994b, Hanford Environmental Information System (HEIS): Volume 2 Operator's Guide, DOE/RL-93-24-2, U.S. Department of Energy, Richl and Operations Office, Richland, WA.

DOE-RL, 1994C, Hanford Environmental Information System (HEIS): Volume 3 Subject Area Reference Manual, DOE/RL-93-24-3, U.S. Department of Energy, Richland Operations Office, Richland, WA.

DOE-RL, 1994d, Hanford Environmental Information System (HEIS): Volume 4 Wellbased Subject Areas, DOE/RL-93-24-4, U.S. Department of Energy, Richland Operations Office, Richland, WA.

DOE-RL, 1994e, Hanford Environmental Information System (HEIS): Volume 5 Surface-based Subject Areas, DOE/RL-93-24-5, U.S. Department of Energy, Richland Operations Office, Richland, WA.

DOE-RL, 1994f, Hanford Environmental Information System (HEIS): Volume 6 Soil Subject Area, DOE/RL-93-24-6, U.S. Department of Energy, Richl and Operations Office, Richland, WA.

DOE-RL, 1994g, Hanford Environmental Information System (HEIS): Volume 7 Sample and Data Tracking Subject Area, DOE/RL-93-24-7, U.S. Department of Energy, Richland Operations Office, Richland, WA (to be issued).

DOE-RL, 1994h, Hanford Environmental Information System (HEIS): Volume 8 Tank Characterization Data Subject Area, DOE/RL-93-24-8, U.S. Department of Energy, Richland Operations Office, Richland, WA.

DOE-RL, 1994i, Hanford Environmental Information System (HEIS): Volume 9 Quality Control Subject Area, DOE/RL-93-24-9, U.S. Department of Energy, Richland Operations Office, Richland, WA (to be issued).

DOE-RL, 1994j, Hanford Environmental Information System (HEIS): Volume 10 Miscell aneous Material Subject Area, DOE/RL-93-24-10, U.S. Department of Energy, Richland Operations Office, Richland, WA (to be issued).

DOE-RL, 1994k, Hanford Environmental Information System (HEIS): Volume 11 Tutorial, DOE/RL-93-24-11, U.S. Department of Energy, Richland Operations office, Richland, WA (to be issued). 
Section REFERENCES

Page

Date

DOE/RL-93-24-5

This page intentionally left blank. 
DOE/RL-93-24-5

\section{DISTRIBUTION}

Number of copies

OFFSITE

2

1

2

ONSITE

4

18
U.S. Department of EnergyHeadquarters

Office of Environmental Restoration and Waste Management (2)

U.S. Environmental Protection AgencyRichland

D. R. Einan

B5-01

WA State Department of EcologyLacey

J. Denkers (2)

WA State Department of EcologyKennewick

J. Yokel

B5-18

U.S. Department of EnergyRichland Operations Office

M. P. Blancq

E. A. Bracken

R. D. Freeberg

Public Reading Room

A5-20

A5-19

A5-19

Al-65

Pacific Northwest Laboratory

D. J. Bates

M. L. Beecroft

R. A. Burnett

D. D. Cabrey

M. A. Chamness

P. J. Cowley

W. E. Cowley

R. W. Deszel1

P. S. Henry

H. H. Kemp

S. L. Legband

J. S. Littlefield

J. K. Merz

N. A. Reitz

J. T. Rieger
K7-34

K7-28

K $7-22$

K7-22

K6-84

K2-22

K $7-22$

K7-53

$\mathrm{K} 6-79$

K7-22

K $7-54$

K7-28

K6-96

K7-22

K6-96 
DOE/RL-93-24-5

\section{DISTRIBUTION (cont)}

S. M. Safford

K7-22

M. J. Sula

Technical Files

SEQUIM

$\mathrm{K} 1-11$

Westinghouse Hanford Company

R. A. Bechtold

H6-07

T. L. Bennington

H4-16

J. S. Bishop

M. K. Britton (2)

S. W. Caggiano

R. A. Casto

C. C. Chamberlain-Dow

H6-07

B4-54

H6-07

H6-07

S. A. Dal thorp

H6-28

L. A. Dietz

H6-07

M. W. Einan

H6-07

R. D. Fox

M. A. Frank

E. A. Gordon

C. D. Kramer

H6-07

H6-07

H6-03

A. L. Patterson

H6-31

H6-04

S. W. Payzant

H6-06

R. D. Price

H6-07

S. L. Reffalt

H6-07

K. J. Scheidegger

H6-07

J. S. Schmid

R. I. Schreck

H6-07

M. R. Schwab

H6-06

H6-07

H6-07

J. A. Serkowski

H6-06

P. J. Walker

A4-35

Central Files

L8-04

EPIC (2)

H6-08

Information Release Administration

(2)

H4-17 


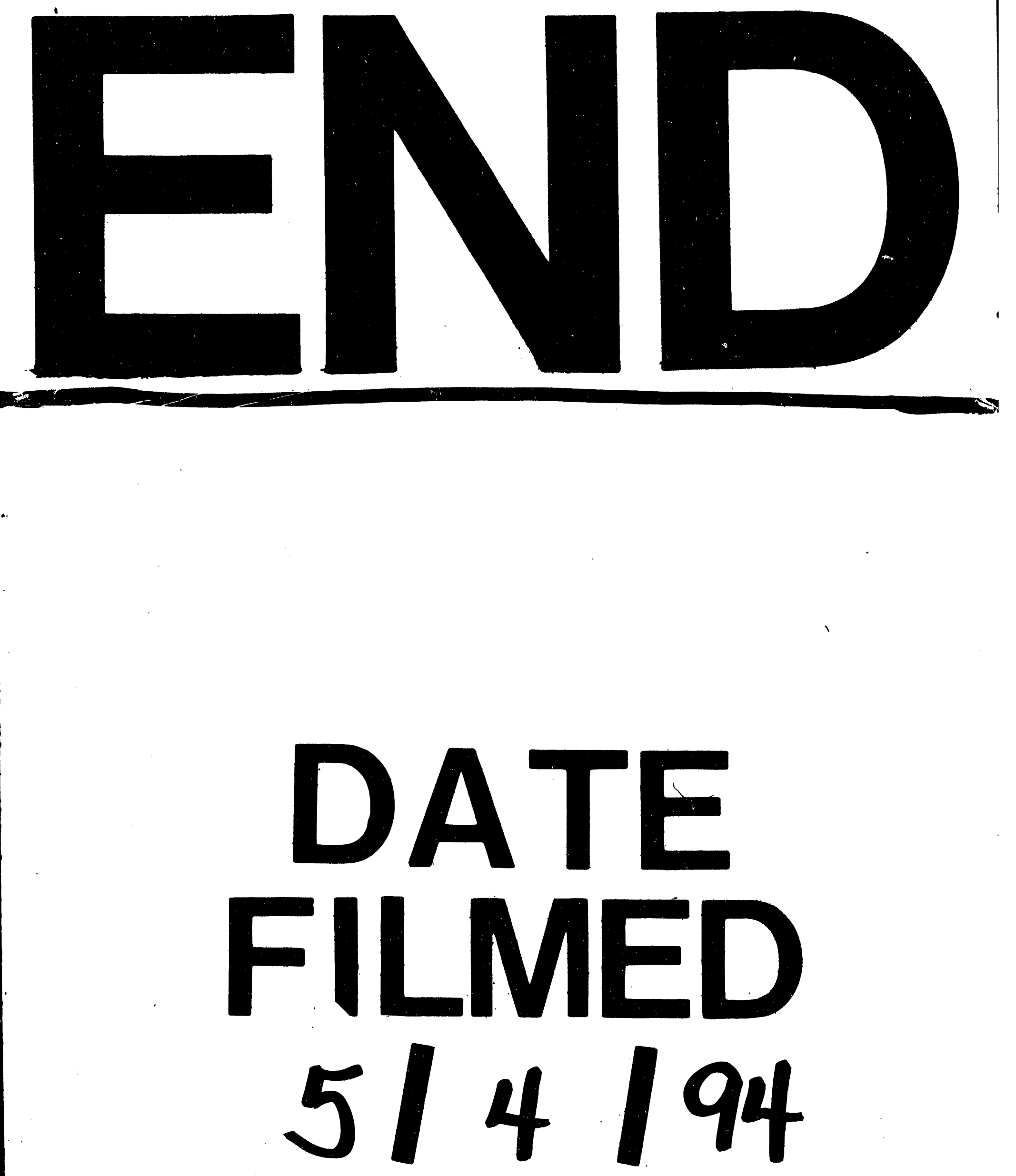


